\title{
Nuevas formas de narrar la memoria en dos novelas sudamericanas contemporáneas*
}

\author{
Cecila López Badano ${ }^{1}$ \\ David Miralles Ovando ${ }^{2}$ \\ Universidad Autónoma de Querétaro (México)
}

\section{Resumen}

La mujer en cuestión (María Teresa Andruetto) y Estrellas muertas (Álvaro Bisama) novelas pertenecientes al ideario contemporáneo, llaman la atención por algunas de sus similitudes temáticas: la memoria de la dictadura. Una, frío informe pretendidamente objetivo; otra, poético recuerdo puesto en abismo, comparten tanto el tipo de personaje central -víctimas femeninas de la represión dictatorial- como cierto mecanismo de construcción literaria donde personajes externos -narradores obligados por diversas circunstancias a reunir pareceres contradictorios- "arman" a las protagonistas. Esto conlleva que, en ambas narraciones, varíe el modo de construcción del sujeto respecto de la narrativa tradicional, puesto que cualquier rasgo introspectivo de aquél se vuelve presuntivo e inaccesible cuando los personajes son compuestos a través de un ambiguo diseño que decantan diversas voces empañadas por la subjetividad, la inconsciencia, la contradic-

\begin{abstract}
La mujer en cuestión (María Teresa Andruetto) and Estrellas muertas (Álvaro Bisama) -novels belonging to the contemporary ideologystand out for some of their thematic similarities: the memory of the dictatorship. One, a cold, supposedly objective report; another, a poetic memory in a mise en abyme, share both the central character type - female victims of dictatorial repression - and a certain mechanism of literary construction where external characters - narrators forced by diverse circumstances to gather contradictory opinions - "arm" the protagonists. This implies that, in both narrations, the subject's mode of construction with respect to the traditional narrative varies, since any introspective trait of the subject becomes presumptive and inaccessible when the characters are composed through an ambiguous design that different voices filter through the subjectivity, the unconsciousness, and contradiction. These South American novels
\end{abstract}

\footnotetext{
* New ways of narrating memory in two contemporary South American novels 1 Dra. por el Department of Romance Languages of the University of Oregon (Estados Unidos). Trabaja en el Centro de Investigaciones Lingüísticas y Literarias de la Universidad Autónoma de Querétaro. Correo electrónico: cecilial@uaq.mx

2 Dr. en Filosofía por la Universidad de Oregon. Coordinador de la Maestría en Enseñanza de los Estudios Literarios de la Facultad de Lenguas y Letras. Universidad Autónoma de Querétaro. Correo electrónico: miralles@uaq.mx
} 
ción. Estas novelas sudamericanas se convierten así en superficies resbaladizas desencantadas del testimonio: más que una biografía, presentifican una red que captura a las protagonistas replicando su encierro: densa telaraña donde el lector avanza entre conjeturas inciertas sobre las ruinas de una personalidad. El objetivo del presente trabajo es explorar esa red a la luz de conceptos como postautonomía (Ludmer), in/ex-timidad (Lacan), contramemoria (Calabrese), resignificando así, a través del desencanto, el sentido de la memoria.

Palabras clave: Memoria, contramemoria, extimidad, postautonomía, Andruetto, Bisama. thus become slippery surfaces disenchanted with testimony: more than a biography, they present a network that captures the protagonists replicating their confinement: a dense web where the reader advances between uncertain conjectures about the ruins of a personality. The objective of this paper is to explore this network in the light of concepts such as post-autonomy (Ludmer), in- / ex-timacy (Lacan), countermemory (Calabrese), thus resignifying, through disenchantment, the meaning of memory.

Keywords: Memory , countermemory, extimacy, postautonomy, Andruetto, Bisama.

Dos novelas próximas en el tiempo, ambas premiadas, pertenecientes al disruptivo ideario alumbrado por este siglo, llaman la atención por algunas de sus similitudes aun en la diferencia que implica siempre la literatura -frío informe pretendidamente objetivo una; poético recuerdo puesto en abismo la otra: La mujer en cuestión (Premio de novela, Fondo de las Artes 2002, reeditada recientemente por Random House) de la argentina María Teresa Andruetto (Córdoba, 1954) ${ }^{3}$ y Estrellas muertas (Premio Municipal de Literatura de Santiago, 2011 y Premio Academia 2011) del chileno Álvaro Bisama (Valparaíso, 1975) ${ }^{4}$.

Sus narrativas tienen en común tanto el tipo de personaje central víctimas femeninas de la represión dictatorial con las consecuencias psicológicas que ello importa, para consigo mismas y para con los demás- como cierto mecanismo de "montaje literario" donde personajes externos -narradores obligados por diversas circunstancias a reunir voces y pareceres contradictorios- "arman" a las volátiles protagonistas femeninas, cuya intimidad -casi incognoscible y abis-

\footnotetext{
3 Hija de inmigrantes piamonteses, primera escritora argentina y en lengua española en ganar el premio Hans Christian Andersen (2012). Licenciada en Letras Modernas por la Universidad Nacional de Córdoba en 1975. Su obra ha sido traducida a varias lenguas, entre las que se cuentan el alemán, el italiano, el portugués y el turco. 4 Escritor, crítico literario y profesor; Magister en Estudios latinoamericanos por la Universidad de Chile; seleccionado en el 2007 por el Hay Festival de Bogotá como uno de los treinta y nueve escritores latinoamericanos más importantes menores de 39 años.
} 
malmente enigmática en su carácter devastado por la violencia de Estado $^{5}$ - es diseñada a partir de un espacio de "extimidad" que las coloca en abismo ${ }^{6}$.

Entendemos acá el concepto de "extimidad", no exactamente en el sentido más actual de la exhibición de la intimidad en las redes sociales, sino como un espacio literario derivado del paradójico significado en que acuña el neologismo Jaques Lacan en su Seminario Sobre la ética del psicoanálisis, de 1958 y reitera posteriormente-como aquello que está más cerca del interior sin dejar de ser exterior- (que también retoma y amplia Alain Miller en un curso dictado en 1985 -luego publicado con el título Extimidad como libro en 2010- de una manera más próxima a la mencionada, más contemporánea). La noción cuestiona la diferencia adentro-afuera; dice Lacan: “[...] lo más íntimo justamente es lo que estoy constreñido a no poder reconocer más que afuera" (1969, s/n). La oposición interior-exterior, mundo interno-mundo externo, es imaginaria. Lo más íntimo es externo.

Lo dicho acerca de esta construcción de lo interior como exterior, externo, reconocible afuera de sí, conlleva que, en ambos textos, varíe radicalmente el modo de construcción del sujeto respecto de la narrativa tradicional, puesto que cualquier rasgo introspectivo de aquél se vuelve presuntivo e inaccesible cuando los personajes son compuestos a través de una confusa "mostración" de los narradores: en una novela (la de Andruetto) se construye desde una aséptica distancia emocional, pretendidamente objetiva a través de voces diversas, contrastivas; en la otra (la de Bisama), si bien existió un compromiso subjetivo y emocional por la relación de amistad entre la narradora en abismo con el personaje central femenino, este "compromiso empático" queda distanciado en el relato a través de esa voz

5 La violencia dictatorial se extendió en Chile desde el golpe de estado contra el gobierno electo de Salvador Allende, el 11 de septiembre de 1973, hasta el 11 de marzo de 1990; en Argentina, desde el golpe de estado del 24 de marzo de 1976 contra el gobierno democrático de Isabel Martínez de Perón, hasta la asunción del gobierno electo de Raúl Alfonsín, el 10 de diciembre de 1983. El saldo del terrorismo de Estado del "Régimen militar" chileno es de más de 28000 personas víctimas de prisión política y tortura, unos 2300 ejecutados y más de 1200 desaparecidos; el del autodenominado "Proceso de reorganización nacional" en Argentina, de unos 30000 desaparecidos (torturados, ejecutados) y aproximadamente 500 niños secuestrados, con la identidad alterada al ser reapropiados por los secuestradores o entregados por estos a familias de su círculo cercano en adopciones ilegítimas. En ambos países, además, muchos habitantes debieron marchar al exilio para evitar la persecución o la muerte.

6 Nos referimos a esta figura literaria con el mismo sentido que aporta la Dra. Helena Beristaín: "Relato interno", "duplicación interior", "narración en primero y segundo grado". Quizá -concluye- "estructura abismada" sea, en castellano, una denominación precisa” (1993-94, 37). 
femenina abismada y mediada por la masculina. Más aun cuando aquella relata reconstruida por la memoria del narrador principal que cuenta en la contemporaneidad un recuerdo intempestivo y ajeno, leja-no, determinando, además, una diégesis de "temporalidad hojaldrada" que enlaza tres momentos diversos: el presente del relato y dos pasados distintos: uno del que el narrador fue partícipe, en un café, con su pareja y a punto de iniciar trámites de divorcio; otro, que él desconocía e involucra a su exmujer, de donde llega el personaje principal femenino que irrumpe en el pasado más próximo a través de la evocación de ella. Además, se rememora un momento de limitada racionalidad en la vida de muchacha estudiante de su expareja, bajo el adormecedor efecto de una droga: jarabe para la tos que la mantenía en un estado semionírico.

Es decir -para evitar confusiones a quien no haya leído la novela-: el narrador es masculino, en un tiempo presente, pero recuerda el día de los trámites de su separación: el pasado más inmediato, años antes, en que su expareja, intempestivamente, en un bar, le cuenta la historia de la Javiera, personaje central, sólo reconstruido por la voz femenina que, a su vez recuerda un pasado más remoto: el de sus estudios universitarios inmediatamente después de la dictadura. La voz femenina, entonces, está mediada -y abismada- por la masculina que recuerda lo que, a su vez, ella le narraba recordando dudosamente, porque en aquel pasado remoto de su vida estudiantil, estaba semianestesiada por una droga. Como se notará a través de la presente descripción, este modo narrativo demuele cualquier certeza, y lo hace de un modo distinto del de la novela de Andruetto: no por contradicción, como en aquella, sino por distancia, mediación y puesta en abismo.

Es interesante considerar en este punto -el referente a la droga y su importancia en el borrado de certezas de la narración- que, según señala Ricardo Piglia (2016): [el psicólogo André] “Green analiza la toxicomanía, es decir la adicción, como un estallido de las formas transaccionales del yo: se pierden todas las mediaciones" (391). Si tomamos en cuenta esta afirmación psicológica, ¿qué distancia nos separa de ese personaje central femenino, ambigua militante en desfasaje temporal, que a su vez, es mediado por una voz masculina recordando el discurso de su exesposa en el momento en que ella había perdido sus capacidades mediacionales en el estallido de las formas transaccionales de su propia identidad? Además, Piglia (2016) señala: "Muchas veces, por ejemplo en Hemingway o en Conrad, el narrador cuenta la historia desde una época posterior a los hechos, por lo tanto no puede transmitir el estado emocional que sentía en el pasado, pero puede pensarlo" (391). Considerando esto, se constata 
cómo la doble mediación -la puesta en abismo-rompe el vínculo con el personaje central: el narrador "definitivo" (masculino), desde una época posterior, no puede recordar, porque esas memorias no le pertenecen, y el personaje femenino -en abismo- no puede transmitir claramente el estado emocional del pasado, cuando la droga la adormecía, y tampoco puede confiar absolutamente en su pensamiento acerca de aquellos momentos. Sin embargo, no se trata sólo de que sea difícil o imposible recordar, sino más bien, de que son recuerdos ambiguos y confusos a los que el relato, a fuerza de retazos, pugna por darles significado. En la espesura de lo que va aflorando en la narración se entrecruzan los sentidos elusivos de varias historias.

Evidentemente, en ambas novelas, la "mostración" de los personajes protagónicos está decantada por la yuxtaposición de diversas voces externas, o bien, puesta en abismo por los vaivenes del decir ajeno en momentos de lejanía, aún del propio yo -estallido de las formas transaccionales del yo que produce el jarabe para la tos en el relato de Bisama, y de otro modo, no menos lesivo, el miedo en la novela de Adruetto-. En la espesura de lo que va aflorando en la narración se entrecruzan, en los dos textos, los sentidos elusivos de varias historias: en una, el narrador no es dueño más que de una catarsis que aflora del dolor y que intenta ser, al mismo tiempo, una explicación, un cierre y una justificación; en la otra, "el informante" pretende despegarse "objetivamente" para evitar la catarsis, el compromiso emocional, o el juicio ético. En consecuencia, se puede deducir que existe una distancia infranqueable que nos separa de esos personajes centrales -ya la Javiera, ya Eva Mondino- marcando con fuerza la imposibilidad de empatía y aún, de una credibilidad no interceptada por dudas y fisuras que ambos discursos hacen visibles, tanto entre los propios personajes narradores como respecto del lector.

Retomando y expandiendo lo argumental de los relatos, diremos que La mujer en cuestión "narra" -o más bien, pretende testimoniardesde la elaborada asepsia de un informe objetivo construido a través de voces de entrevistados que se contradicen en sus afirmaciones, escrito, además, por "el informante" respondiendo a un anónimo encargo evidentemente remunerado, la historia de Eva Mondino, muchacha secuestrada durante la dictadura argentina y sobreviviente de uno de los más sanguinarios campos de concentración del país: el tristemente célebre "La Perla", en la provincia de Córdoba. Las voces "constructoras" consultadas resultan así indeleblemente empañadas por la subjetividad, la inconsciencia, el miedo, la complicidad con el régimen dictatorial. Es decir, plantean, en definitiva, la contradicción entre visiones divergentes y convierten su contenido en factor distante de cualquier posibilidad 
de certeza, tiñendo de indeterminación el realismo que, al tiempo de ser presentado incluso con el mencionado formato testimonial, se contradice en éste, y se vuelve "realismo impreciso" autonegándose en la imposibilidad absoluta de un certero conocimiento humano. Allí, como señala Pampa Arán (2005a), el efecto de real "desborda el marco de una reconstrucción histórica y del pacto de lectura del realismo tradicional para mostrar, más que un saber sobre lo real, su problematización desde el presente" (24).

Estrellas muertas, por otra parte, narra la historia de "La Javiera", militante de las juventudes comunistas y eterna estudiante universitaria a pesar de andar ya en sus cuarentas. Se trata de una "retornada", término con el que se designaba a los exiliados que lograban reingresar a Chile después de sufrir el exilio. ${ }^{7}$ Tal vez por ello, "el partido" hacía la vista gorda con respecto a su edad, como si los años del exilio constituyeran un paréntesis en que no había transcurrido el tiempo y como si su reinserción en la sociedad tuviera que producirse exactamente en el tiempo y circunstancias de las que fue violentamente arrancada. La Javiera está viviendo pues, aquella parte de su existencia que le fue escamoteada por la dictadura de Pinochet. No es extraño entonces que inicie una relación con el joven estudiante conocido como "El Donoso," quien, a pesar de la diferencia de edades, pasa a ser su pareja sentimental. Esta dislocación del tiempo es una característica muy común en los exiliados "retornados", quienes parecen abonar la idea de volver a un país congelado en la memoria, uno que, sin embargo, ya no es el que se vieron obligados a abandonar, pero que sigue instalado en sus cabezas. De este modo, aunque la novela nos sitúa en plena post dictadura, en el continuismo político y económico ejercido por los gobiernos de "la concertación," y que se trata en realidad de un espacio/tiempo articulado por dos épocas que se interceptan sin que sea fácil discernir hasta qué punto son realmente diferentes, sus protagonistas viven en imaginarios acrónicos a pesar de que cohabitan en la misma historia.

La novela de Bisama se articula en diversos niveles diegéticos y se entiende que la historia que enmarca a la principal se relaciona con ésta, precisamente porque es el momento de un final, de una ruptura: la ruptura de la relación entre el narrador y su pareja. Es ella en realidad quien "cuenta" la vida tormentosa de "La Javiera" y lo hace, tal vez, como una manera substituta de lamentar su propia quiebra. La estrategia del discurso narrativo conecta, así, no sólo dos tempo-

7 Resulta interesante recordar que este término fue usado primero para designar a los esclavos de origen africano que regresaban a la tierra natal de sus padres o abuelos. Y en este caso como el de aquel, se trata de la vuelta a la tierra de la que fueron arrancados con violencia. 
ralidades diversas, sino también dos finales, dos historias en su momento de cierre: el encarcelamiento de "La Javiera", que aparece esa mañana como noticia, con la foto de la mujer esposada en las páginas del diario porteño La Estrella de Valparaíso, luego de un crimen pasional, y el final del matrimonio del narrador: "Si es ahí donde comienza lo que ahora termina." (Bisama, 2010: 19). La yuxtaposición del relato de "La Javiera" en boca de la esposa de éste, es también una forma de explicarse el fracaso propio, puesto que su relato introduce a menudo secuencias de la vida de ella que, en su carácter colateral, perfilan su inestable relación con la realidad. Por ejemplo, precisamente, cuando revela su adicción al punk y a una droga: "Mi verdadera vida era secreta, nadie sabía que escuchaba punk y bebía jarabe para la tos..." [...] "Fui adicta casi dos años. Nadie se dio cuenta." (93).

Ambas historias -la de Andruetto y la de Bisama- son también las de la quiebra definitiva de una forma de vida; tanto la decadencia como el aislamiento de las protagonistas representan, además, el fracaso de una manera de concebir la sociedad y las relaciones entre sus individuos: la quiebra de los lazos solidarios construidos por el ideario de la utopía sociopolítica, como "horizonte regulador ético del presente", ante el avasallamiento brutal de las dictaduras. En Estrellas... es aún más clara que en La mujer... la cohabitación ambigua de proyectos utópicos reavivados desde sus restos con el más duro pragmatismo de nuevas ideologías, que no podía sino confundir a los ciudadanos: esta convivencia caótica define, entonces, un espacio donde la impostura y la simulación se entrelazan con idealismos trasnochados terminando por configurar una realidad inestable y huidiza.

"La Javiera" nunca podrá conectarse del todo ni con "El Donoso" ni con el resto de sus compañeros: vive agresivamente, en un agonismo ${ }^{8}$ a ultranza en medio de un contexto en absoluto diferente de aquel que, obligada, había dejado: un mundo en el que ella ya no cabe; Eva Mondino no podrá retomar relaciones de sana convivencia con los seres de su entorno: sobrevive, entonces, desintonizada en un letargo temeroso, en una agonía atónita. Ello -para la Javiera- evidentemente no es sólo una cuestión de edad; tampoco, para Eva, una de "familiaridad": estarán girando siempre en una órbita que es tanto la de su pasado individual, propio de ellas -esa intimidad imposible de reconstruir por los de afuera- como también la del de quienes, como ellas, fueron arrancados con violencia de la historia y se quedaron sin historia. Lo monstruoso o lo patético de ambas novelas es, justa-

8 Utilizamos este término en el sentido de cierta teoría política que ve como potencialmente positivo el conflicto político, difiriendo de la descripción de la democracia como la búsqueda de consensos. 
mente, este descentramiento de los personajes, ese relato que vuelve éxtimo lo íntimo irrecuperable.

Ambas narrativas se plantean entonces como resbaladizas superficies ambiguas, desencantadas del testimonio: más que seguir una línea biográfica, presentifican fragmentariamente una red que captura a las protagonistas replicando su encierro, su desesperación, su exclusión social, una densa telaraña donde el lector avanza a tientas, entre conjeturas e intuiciones, sobre las ruinas de lo que fuera una personalidad, misma que, en el presente del relato, ya ha sido desmantelada, volatilizada, e incluso, condenada.

En una forma bastante inédita, se componen biografías que autoniegan e impugnan la propia posibilidad biográfica ante lo que queda exhibido como la impotencia casi absoluta, radical, tanto por parte del narrador como del lector, de acceder a un conocimiento humano frontal, que vaya más allá de la mera especulación acerca de las personalidades "en cuestión", sobre todo, si se tiene en cuenta que, lo que se evidencia en la expresión del "juego" narrativo textual, es la imposibilidad manifiesta, bajo las formas dictatoriales, de la propia existencia de una identidad íntegra, plena y no saqueada por la violencia que las ha convertido en identidades descentradas, fugitivas, en conflicto; personas -y personajes en el sesgo narrativo testimonial- vaciadas o tóxicas. En estos relatos, más allá de la experiencia traumática, incluso el género (gender) se desdibuja para desnudar la condición humana primordial ante situaciones extremas. Una afirmación del escritor Juan Martini respecto del texto de Andruetto puede hacerse extensiva a ambos relatos: "Una novela extraordinaria que aborda el tema de la identidad como correlato inexcusable de la violencia, el horror y la muerte que desencadenó la última dictadura. El hallazgo formal de esta historia vibrante es un motivo más para internarse en la reconstrucción de una vida borrada" (Cit. en https://books.google.com.mx/books/about/La_ mujer_en_cuestion.html?id=H_P4-Vo7NtUCredir_esc=y)

¿Cómo examinar estas nuevas narrativas, que son, a su modo, anamnéticas y constructoras de una prosa realista que, a la vez -como a la propia memoria- rompen y desmaterializan? Entre las concepciones recientes de índole teórico ensayística, se encuentra un grupo de conceptos que permiten interpelar su condición innovadora, por ejemplo, el de postautonomía, acuñado por Josefina Ludmer, explorado antes de su publicación como artículo en el libro Aquí América Latina (2010) y retomado por Florencia Garramuño (2009). Este tipo de textos "postautónomos" "se instala en un régimen de significación ambivalente y ése es precisamente su sentido", es decir, se insertan entre aquellos que paralizan el juicio literario y dramatizan 
el proceso de cierre de la literatura autónoma abierto por Kant y la modernidad y de la lógica interna y las instituciones que la sostenían, a los que Ludmer caracteriza como:

Escrituras [que] pedirían, y a la vez suspenderían, el poder de juzgarlas como 'literatura' [...] son constituyentes de presente [...] reformulan la categoría de realidad: no se las puede leer como mero 'realismo', en relaciones referenciales o verosimilizantes [...] salen de la literatura y entran a 'la realidad' y a lo cotidiano, a la realidad de lo cotidiano (y lo cotidiano es la TV y los medios, los blogs, el email, internet, etc) [...] toman la forma de escrituras de lo real: del testimonio, la autobiografía, el reportaje periodístico, la crónica, el diario íntimo, y hasta de la etnografía [...] Ahora, en las literaturas posautónomas ('ante' la imagen como ley) todo es "realidad" y esa es una de sus políticas. Pero no la realidad referencial y verosímil del pensamiento realista y de su historia desarrollista (la realidad separada de la ficción), sino la realidadficción producida y construida por los medios, las tecnologías y las ciencias. Una realidad que es un tejido de palabras e imágenes de diferentes velocidades y densidades, interiores-exteriores al sujeto (que es privadopúblico). Esa realidadficción tiene grados diferentes e incluye el acontecimiento pero también lo virtual, lo potencial, lo mágico y lo fantasmático; es una realidad que no quiere ser representada o a la que corresponde otra categoría de representación (2010: 150-151).

Obviamente, en ambas novelas, las características apuntadas se manifiestan cuando están escritas como límite deliberado entre la realidad y la ficción, lo que se acentúa en el caso de Andruetto con su escritura descarnada, "desauratizada" respecto de la estética literaria anterior, escritura que opera entre la memoria y lo irreconstruible de ésta en la inmediatez del trauma que alteró las vidas particulares convirtiendo a los personajes centrales en presencias desmaterializadas, en sujetos vaciados. En su carácter, ya testimonial, en el caso de Andruetto, ya lindante con informaciones massmediáticas estetizadas en el de Bisama -es una fotografía del diario lo que desencadena el relato-, son fronterizas y rompen con los géneros que habían intentado construir la memoria lidiando entre la materialización estética del trauma y su indecibilidad. De allí que cobre importancia el espacio psicológico de "lo éxtimo". 
La mujer en cuestión, a través de su formato de informe encargado al narrador "informante" por alguien anónimo - "el mandante", sustantivo incriminatorio con el que se consigna su presencia y entidad externa al texto en el relato- suspende el juicio literario e instituye un nuevo presente y una nueva realidad en cada testimonio diverso que este "informante" recoge -incluido el de la propia víctima- opinando sólo en contadas ocasiones. Dice Samuel Zaidman:

\begin{abstract}
Para llevar adelante su investigación, el narrador ha entrevistado a más de treinta personas. El informe es un género que exige objetividad e imparcialidad, y el informante aquí es, además, puntilloso y obsesivo: con la minuciosidad de un burócrata, cada dato obtenido es presentado como cita y registrada su fuente y, al mismo tiempo, se considera necesario intercalar numerosas notas aclaratorias (2009: s/n).
\end{abstract}

Al ficcionalizar textos de procedencia diversa y especialmente aquellos de origen no fictivo, pone en cuestión su legitimidad y permite el juego de las interpretaciones valorativas generando con ello lo que Elisa Calabrese denominó “contramemoria” (1994: 66; 2009: 22). Además, los testimonios se contradicen, lo que genera que, si bien le es permitido al lector entrar en ese juego de interpretaciones valorativas, éstas desacreditan toda certeza, vaciando psicológicamente al personaje y produciendo el efecto de devastación, de reconstrucción externa (lo éxtimo) en que se conoce lo interno (lo íntimo indecible).

Esa "contramemoria" se gesta en la mencionada novela desde la pretendida objetividad del compilador construyendo el informe y desde la completa -aunque nunca exhaustiva- recolección de datos testimoniales. Con ello se destaca, aún en la profusión de voces y acentuada por la contradicción "la laguna del saber, el dato ausente, [...] un modo oblicuo de señalar el vacío" (Calabrese, 2009: 22). El lector, aunque supuestamente asiste al registro de los hechos, sólo tiene enfrente la escritura de la contradicción.

El texto es, al mismo tiempo, testimonio y ficción: su género es el límite, la confluencia; se crea un modo testimonial "falsificado" a través del cual se anulan los procesos de certidumbre que el lector espera, sobre todo, de aquel tipo de literatura; rompe con una estética convencional -reconstructiva- de la memoria y a la vez, adquiere un perturbador carácter de vigilancia panóptica cuando no sabemos, en ningún momento de la lectura, quién ha encargado -y pagado por-el informe, ni para quién la propia protagonista volátil -presionada por la necesidad de dinero- se presta a hablar. El "mandante" -externo, 
anónimo, fantasmal, pero aun así, proveedor interesado y controlador cuyos fines desconoce el narrador y también el lector- podría ser, entonces, el enemigo - ¿el Estado?- tratando de indagar acerca de si logró o no destruir totalmente a su víctima y en qué punto está ella ahora. En consecuencia, los lectores pasamos a ser espías y cómplices -como el mismo narrador aun en su elaborada objetividad aséptica-, pero también voyeurs de lo mismo, de lo incierto, del asfixiante carácter persecutorio que, en la indagación, convierte lo privado en público, lo íntimo en éxtimo. Ampliando la categoría de "persecutorio", incluso podemos pensar que todos estamos bajo vigilancia y, como en el multicitado texto de Brecht, que vendrán por nosotros en cualquier momento.

En la novela de Bisama, la "contramemoria" -como suma de fuentes fictivas e históricas, político-testimoniales y estético-literarias en tensión entre sí (Calabrese, 1994: 66)- adquiere un poético carácter apocalíptico. Como ya se dijo, la narración se inicia con el recuerdo masculino de una ya distante mañana temprano, en el café Hesperia de Valparaíso. No es arbitrario que, como escenario del relato, la ciudad elegida -por su paisaje "sitiado"- sea ésa: al oeste el mar, y el resto, bosques ardiendo en las montañas; no hay por dónde escapar sin arder o naufragar:

[...] los bosques de Laguna Verde se estaban quemando y el viento que venía del sur lanzaba el humo negro sobre el horizonte de los cerros. Con ese cielo oscuro sobre el puerto, yo no dejaba de pensar en que esas cenizas que flotaban en el aire podían ser parecidas a las de los hornos de un campo de concentración, a la borra de piel humana que deja una bomba atómica (I:11).

En medio del devastador incendio forestal, entre su humo y sus cenizas -con ese aludido parecido catastrófico a los de un campo de concentración o a las consecuencias de un estallido atómico- una pareja -que él entonces integraba- espera para iniciar sus trámites de separación en las oficinas cercanas cuando ella ve en el diario la fotografía de una mujer condenada a prisión por un crimen pasional familiar: su ex compañera de universidad en los primeros 90, mayor que ella, torturada y exiliada en los 80 , militante de la juventud de izquierda.

La imagen apocalíptica del paisaje, además del gran cuadro de un naufragio en la pared -el mejor símbolo para lo que a ambos narradores les acontece-, aunque sea a un nivel simbólico, permite imaginar que allí, en ese escenario, análogamente, las vidas -al menos las 
de los personajes de esta ficción- habrían de transcurrir bajo el agobio y la desesperación. La novela trabaja en una suerte de racconto, fragmentando las claves enterradas o inconscientes de ese pasado, por otra parte, reciente, que explicaría el naufragio de toda una generación. Una juventud que ya roza la madurez y que parece constatar que aquella alegría prometida por la primera democracia nunca va a llegar y que, por el contrario, han vivido y están viviendo una época bastante siniestra. El carácter fragmentario del recuerdo reflejado en el discurso del relato, habla también de una cierta incoherencia y una dislocación de la vida transcurrida en aquel momento: esta combinación de elementos es paralizante, congela el devenir. Así, en el fragmento final -el 84- se dice, a modo de cierre desesperanzado:

\begin{abstract}
Todo lo que yo conocía se extinguió. La humanidad completa se volvió una legión de vampiros, una multitud de ratas detenidas en medio de la pista de baile, a centímetros del despeñadero. Nunca más volvimos al Hesperia. Entre nosotros, en algún momento del futuro, sobrevino el llanto. Nos comportamos como animales, nos comportamos como personas. Nunca salimos de ese café. Nunca nos fuimos de ahí, nunca abandonamos realmente el puerto. La ciudad se quemó, desapareció. El cielo se llenó de estrellas muertas (187).
\end{abstract}

Ese racconto, en abismo, pues el narrador recrea aquella ya distante conversación en el bar, lo hace la mujer a través de esa voz masculina que rememora aquello que le fue dicho angustiadamente por su casi expareja al descubrir la fotografía de su antigua compañera de clases, pero la muchacha, a su vez, como ya se señaló, recuerda -y reconstruye fragmentariamente- la historia de aquella otra mujer de la fotografía contemporánea al momento del relato -los 90-, tan destruida como el paisaje de los bosques humeantes. La postura sobre la imposibilidad de certidumbre para la memoria es similar a la de la otra novela, una cita puede corroborarlo:

Dijo: alguna vez escuché a una mujer belga en una conferencia hablar de eso. De qué es lo que significa ser testigo. ¿Sabes qué dijo? Dijo que era imposible escribir cualquier clase de testimonio, porque la idea misma es superflua y falsa; porque lo que recordamos de nuestro pasado, de la vida de los otros, son apenas fragmentos machacados, momentos sueltos que intentamos unir y pegar para que reemplacen a la experiencia, para que sean la experiencia, dijo ella. Pero cuando esa experien- 
cia es pura catástrofe, la vida de los otros emerge como el fondo de un cuadro, borrosa, y emerge tal y como sale la Javiera en esa foto del diario ahora, hecha una silueta difusa, vuelta una sombra de si misma, dijo ella. Una ilusión. Un fantasma. Así, no podemos hacer nada más que pensar en que la idea del testigo es una imbecilidad. Porque contar algo no nos sirve de nada, es un esfuerzo que resbala en un piso hecho de barro, dijo ella y luego agregó: En realidad no sé si eso era lo que decía la mujer belga. Quizás decía lo contrario. Que ese era el único esfuerzo que había que hacer, a pesar de su inutilidad (59).

David Rieff en Elogio del olvido. Las paradojas de la memoria histórica (2017), comenta: "la esencia de la rememoración histórica la construyen la identificación y la proximidad psicológica en mayor medida que la exactitud histórica, por no hablar de los matices históricos y la profundidad" (43-44). La visión desencantada de la memoria -o más bien, la imposibilidad de construirla unívocamente- memoria que en los textos en cuestión, no sólo es individual, sino también, claramente, histórica, marca, en conjunción con la cita de Rieff, un problema: si la identificación y la proximidad psicológica son nucleares para la rememoración ¿qué sucede cuando ambas están rotas?

En su carácter de narrativas postautónomas o -en el caso de Bisama- en las que transitan un delicado borde entre autonomía y postautonomía literaria ${ }^{9}$, estos relatos ponen de manifiesto que es imposible responder la cuestión planteada desde el punto de vista de las categorías de la autonomía, asentadas también sobre una construcción de sujeto -de personaje- que no es la que se establece en éstas; por ello es conveniente explorar otro tipo de categorizaciones, que es lo que pretendemos a través de la noción de extimidad.

Retomando, entonces, las palabras de Rieff, puede decirse que en la novela de Andruetto, la técnica del informe, factura que, como ya se-

9 Es, justamente, tanto en el "cómo" de la puesta en abismo de las voces que se distancian, como en la utilización del enturbiamiento "sahumado" de la escena del recuerdo, donde la novela juega sus recursos "autonómicos", mientras que el "qué" de la vida militante de la Javiera y su pasado político atormentado, ejemplificador del desencanto y la siniestra devastación histórica de una generación, se aproxima a lo postautónomo en su vinculación con la historia política nacional, en su "constitución de presente". Es necesario aclarar que no se debe malentender el concepto de "postautonomía" como un intento de "hacer aparecer algo como real", sino con el juego realidad/ficción: esto implica tanto el vuelo literario de algunas escenas, como el "cable a tierra" de la mención a políticos, la introducción del periódico y la crónica policial, la realidad histórica constatable. 
ñalamos, elude los recursos formales esteticistas de la autonomía, al invalidar su categoría verosimilizadora en la autocontradición, anula cualquier posibilidad de identificación, de empatía con un personaje finalmente incognoscible; en la de Bisama, se marca una distancia insalvable también con la proximidad psicológica a través del distanciamiento y la incomprensión de las voces narrativas que construyen al personaje de la Javiera: los vínculos intersubjetivos quedan rotos por la distancia temporal que estratifica el relato y agravada por el estado de anonadamiento, de semi cancelación de la conciencia de la muchacha (pre)narradora cuya voz es, como ya se dijo, puesta en abismo por el narrador masculino "definitivo" que "decanta" el relato femenino. Ese abismo, además, no sólo es lejanía de las voces, sino también, insalvable cesura temporal que desdibuja y nubla el pasado, asfixiándolo, como lo hace el humo invasor con la ciudad en la escena intoxicada del recuerdo.

Si se anulan ambos factores -identificación y proximidad psicológica- ¿cómo se construye entonces el sujeto? Indudablemente, ya no es desde la motivación íntima a la que nos tenía acostumbrados la literatura anterior: si bien la omnisciencia se había perdido hace ya tiempo, quedaban los vectores formales que iban del yo narrando en primera persona para construir su propia intimidad, al testigo limitado, que reconstruía parcialmente lo que compartía de la intimidad del otro; en cambio, ahora, ningún testigo está seguro de lo que ha visto, de lo que ha escuchado, de lo que creía haber conocido; tampoco puede, por consiguiente, reconstruirlos el lector a través de él, ni siquiera, como sospecha a partir de la superposición de versiones: se ha cancelado el conocimiento de la intimidad y se pasa a las incertidumbres cognitivas de la extimidad, que lee la intimidad desde lo externo, desde lo tentativo.

Así, esas mujeres están, en estas novelas, exiliadas de sí mismas; su ser íntimo se dibuja en lo más lejano y deslocalizado de su interioridad, pero es apenas reconstruible en la destrucción que la violencia ha ejercido sobre ellas: violencia estatal que ultrajó su ser para convertirlas en vaciados fantasmas. En un caso, da cuenta de ello el informe testimonial contradictorio; en el otro, la distancia narrativa, la adicción que nubla la conciencia, la voz masculina que mediatiza el relato del recuerdo, distanciándolo aún más, etc. De todos modos, tanto el encarcelamiento de la Javiera en una, como el temeroso letargo aislado de Eva, son los momentos del futuro -en la primera- o del presente -en la segunda- en que se revelará el poder ya represivo, ya desprotector, que la democracia ejerce ahora vicariamente, pero con la misma violencia o la misma indiferencia que la dictadura. 
En la simbolización escritural que intenta trabajosamente restablecer la identidad perdida focalizándose entre la borradura de lo íntimo y la categoría de lo "éxtimo" -esta última representada por la reconstrucción que hacen los informantes y/o los narradores de las inciertas motivaciones de lo íntimo- se entrevé lo no dicho, lo siniestro; en ese espacio ficcional, donde el realismo de los recursos formales -entrevistas, conmemoración de momentos compartidosal tiempo que se enuncia, se autocontradice, anulándose, porque no hay posibilidad de conocer la realidad de esos personajes. A propósito de ello, dice Arán en una ponencia:

En la novela de Andruetto, dos epígrafes abren el relato como una secreta advertencia, uno en inglés cuya traducción aproximada sería "Si yo pudiera atrapar la oscuridad / con los ojos abiertos" y la otra "El mundo parece plano, / pero yo / sé que no lo es". Ambas citas aluden a los límites de toda visibilidad y de toda experiencia sensible ¿cómo ver en lo oscuro? ¿Cómo percibir la verdad tras las apariencias? Operaciones del ojo y de los sentidos ante las que cualquier proceso de cognición inmediata fracasa. Sólo es posible entrever, suponer, conjeturar ya que lo que se muestra es incierto, sospechoso o falso (2005b).

En el intersticio que dibujan las incertidumbres acerca de lo íntimo, se da cuenta, aun sin ser una reconstrucción, de treinta años de historias nacionales, y las personalidades avasalladas de ambas protagonistas surgen como "éxtimo" en los relatos. Esa construcción presuntamente objetiva de La mujer... -que, a pesar de ser inversa de la del personaje de La Javiera, tan subjetiva, pero también plena de dudas, pone de relieve lo mismo- sólo permite atisbar "una sombra enfatizada por el contraste" (Zaidman) entre lo banal que emerge como dato recuperado y lo contradictorio de los testimonios confrontados o, según Arán "no tanto lo que está en las palabras, sino lo que se oculta, lo no dicho, lo que está, estuvo o sigue estando, más allá de las palabras, en otra parte, una parte negada de la historia, personal y colectiva" (2005b). Por ello, en eso éxtimo, contradictorio, conjetural -siniestro-, no sólo pueden reconocerse ellas, sino que reconocemos el fracaso y la parálisis de los sobrevivientes de una generación avasallada, que es también lo íntimo indecible de quienes hemos padecido, de modos menos torturantes, las dictaduras latinoamericanas, visibilizado en lo éxtimo, siniestro, de estos relatos. 


\section{Bibliografía}

Andruetto, M. T. (2014). La mujer en cuestión. Buenos Aires: Random House.

Arán, P. (2005a). Biografías no autorizadas: la identidad del héroe. En: S. Romano

Sued y P. Arán (Eds.). Los '90. Otras indagaciones. Córdoba: Epoké. . (2005b). Temporalidad y narratividad en historias de vida. Novelas de Andruetto y Schmucler. II Foro de Investigadores en Literatura y Cultura Argentina. Universidad Nacional de Córdoba.

Beristain, H. (1993-94). Enclaves, encastres, traslapes, espejos, dilataciones (la seducción de los abismos), Acta Poética, 1415, UNAM.

Bisama, A. (2010). Estrellas muertas., Santiago: Aguilar ChilenaAlfaguara.

Calabrese, E. T. (1994). Historias, versiones y contramemorias en la novela argentina actual. Itinerarios entre la ficción y la historia. Buenos Aires: Grupo Editor Latinoamericano. (53-71). - (2009). Lugar común. Lecturas críticas de la literatura argentina. Mar del Plata: EUDEM.

Garramuño, F. (2009): La experiencia opaca. Literatura y desencanto. Buenos Aires: FCE.

. (2015): Mundos en común. Ensayos sobre la inespecificidad en el arte. Buenos Aires: FCE.

Lacan, J. (1969). Seminario 1968/9. Clase 14, 12 de marzo. http:// www.psicoanalisis.org/lacan/16/14.htm

Ludmer, J. (2006): Literaturas postautónomas. http://www.loescrito.net/index.php?id=158. Texto perfeccionado y ampliado en "Identidades territoriales y fabricación de presente". Aquí América Latina. (2010) Buenos Aires: Eterna Cadencia. (149-156).

Martini, J. (s/f). Cit. En https://books.google.com.mx/books/about/ La_mujer_en_cuestion.html?id=H_P4-Vo7NtUCredir_esc $=y$.

Piglia, R. (2016). Los diarios de Emilio Renzi. Los años felices. Ciudad de México: Anagrama. 
Rieff, D. (2017). Elogio del olvido. Las paradojas de la memoria histórica. Trad. Aurelio Mayor. Bogotá: Pinguin Random House. Debate.

Zaidman, Samuel. (2009). Una mujer entre paréntesis. Buenos Aires: Página 12 (Radar libros), 2 de agosto. https://www.pagina12.com.ar/diario/suplementos/libros/10-3516-2009-08-02.html 